\title{
Adaptational changes in physiological and transcriptional responses of Bifidobacterium longum involved in acid stress resistance after successive batch cultures
}

\author{
Yanxia Wei ${ }^{*}$, Jing Gao ${ }^{\dagger}$, Dianbin Liu ${ }^{\dagger}$, Yang Li and Wenli Liu
}

\begin{abstract}
Bifidobacterium inhabiting the human and animal intestinal tract is known for its health-promoting effect. Tolerance to acid stress is crucial for bifidobacteria to survive and then exert their beneficial effects in the gut. A long-term adaptation in successive batch cultures was used as evolutionary engineering strategy to improve acid stress tolerance in an industrial probiotic strain, B. longum JDM301. Its derivative, JDM301 AR showed higher resistance to several stress conditions, including acid stress than the parental strain, JDM301. To better understand bifidobacterial acid stress response, the changes of fatty acid (FA) in cell membrane of these two strains were determined. A shift in the production of FA in cell membrane, characterized by increased C14:0 was found, when JDM301AR was exposed to low-pH environment. It was implied that the increased production of C14:0 is associated with the acquisition of acidtolerant phenotype for JDM301AR. High-throughput RNA-sequencing was performed to analyze the changes of gene expression profile after acid-exposure. The transcriptional profiles of JDM301AR and JDM301 under normal condition and acid stress were compared to reveal the different acid response between them. A total of 5 genes involved in FA metabolism were upregulated and no downregulated genes were found in response to acid stress in JDM301AR. The up-regulated BLJ_0565 and BLJ_1105 may play important roles in the modification of membrane FA composition of JDM301AR after acid exposure. Overall, these results suggested that successive batch cultures induced the acid stress tolerance of $B$. longum involved in transcriptional and physiological responses, including modification of cell wall and cell membrane, metabolism of amino acid and neutralization of internal pH by strengthening $\mathrm{NH}_{3}$ production and transport.
\end{abstract}

Keywords: Bifidobacteria, Adaptive evolution, Acid stress, Cross-protection, Fatty acid

\section{Background}

Bifidobacteria are anaerobic and Gram-positive bacteria mainly inhabiting the human and animal intestinal tract. It was believed that bifidobacteria can strengthen the intestinal barrier, modulate the immune response, inhibit pathogens and so on [1]. However, during the industrial manufacturing processes and passage through

\footnotetext{
*Correspondence: weiyx2007@aliyun.com

${ }^{\dagger} Y a n x i a$ Wei, Jing Gao and Dianbin Liu contributed equally to this work

Jiangsu Key Laboratory of Immunity and Metabolism, Laboratory of Infection and Immunity, Department of Pathogenic Biology

and Immunology/School of Stomatology, Xuzhou Medical University, Xuzhou 22104, Jiangsu, China
}

the digestive tract of the host, bifidobacteria encounter various types of stress, which can reduce bifidobacterial viability and probiotic effects. In particular, bifidobacteria used as probiotics, need to survive the acid barrier of the stomach [2]. The acid barrier represents a major challenge for probiotics. The results of clinical trials implied a direct dose-effect correlation with probiotic efficacy [3]. Overall, acid tolerance is critical to bifidobacterial survival and therefore to the functionality of various probiotic products.

The resistance of bacteria to lethal stress can be improved by application of sub-lethal stress during culture, which called stress adaptation. The acid adaptation 
has been reported in Bifidobacterium longum (B. longum) and Bifidobacterium animalis (B. animalis) and in several other gram-positive bacteria such as Streptococcus mutans, Enterococcus faecalis [4-7]. In previous reports, B. longum $8809 \mathrm{dpH}$ and BBMN68 mutant strain showing enhanced acid tolerance compared with the wild-type strain were isolated by culturing cells in low $\mathrm{pH}$ pressure achieved through modified medium with hydrochloric acid $(\mathrm{HCl})$ [5]. Although acid tolerance response of $B$. longum has been studied in previous reports, the adaptation mechanisms revealing acid stress response in bifidobacteria are still largely unknown.

In our study, the acid tolerance of B. longum JDM301, an industrial probiotic strain was improved only by successive batch cultures in normal condition [cultured anaerobically in De Man-Rogosa-Sharpe (MRS) supplemented with $0.05 \%(\mathrm{w} / \mathrm{v}) \mathrm{L}$-cysteine- $\mathrm{HCl}$ at an initial $\mathrm{pH}$ of 6.5 at $37^{\circ} \mathrm{C}$. This study provided an approach to improve bifidobacterial tolerance response in normal condition and a first insight into the stress cross-protection, the alterations of the gene expression patterns and the changes in cell membrane lipids of industrial bifidobacterial strain achieved by adaptive evolution through successive batch cultures without additional stress. The purpose of this study was to investigate the transcriptional and physiological responses of two closely related strains of B. longum JDM301 (JDM301), a widely used strain in China [8] and its acid-resistant derivative $B$. longum JDM301AR (JDM301AR), a strain obtained by successive batch cultures of JDM301. The different responses of the acid-resistant strain was compared with its parental strain, JDM301. To reveal the differences of gene transcription between JDM301 and JDM301AR potentially responsible for acid resistance and the crossprotection, the transcriptional response profiles of JDM301 and JDM301AR cultured under normal condition were analyzed and compared. To further reveal the mechanism underling the acid resistance in JDM301AR, JDM301 and JDM301AR were exposed to acidified culture medium and the gene transcription of each strain in acid condition was compared with that in normal condition, respectively. B. longum JDM301 was chosen based on its wide use in industry as probiotic in China and the availability of complete genome sequence information [9] to reveal the adaptive evolution of bifidobacteria through successive batch cultures in normal condition.

\section{Results and discussion}

\section{Enhancement of the stress tolerance of JDM301} after adaptive evolution

To study the effects of successive batch cultures (150th repeats) on the stress tolerance of $B$. longum, cells were collected and transferred into acidified MRS medium
$(\mathrm{pH}=3.5)$, MRS with $0.5 \mathrm{M}$ sodium chloride $(\mathrm{NaCl})$ or containing $1.25 \mathrm{mM}$ hydrogen peroxide $\left(\mathrm{H}_{2} \mathrm{O}_{2}\right)$. The cells (JDM301AR) showed significantly higher survival rate than the non-adapted strain (JDM301) after $1.5 \mathrm{~h}$ incubation under acidified medium. Furthermore, JDM301AR displayed higher tolerance to osmotic and oxidative stress, when compared with JDM301 (Fig. 1). Crossprotection response has been reported in several other bacteria, such as Escherichia coli, Vibrio harveyi and Lactococcus lactis [10-12]. A cross-protection mechanism between bile and acid stress was discovered in B. animalis [13]. The results in our study showed that successive batch cultures provided this bacterium with cross-protection against several stress conditions [14].

\section{Differences of gene transcription profile between JDM301 and JDM301AR under normal condition}

Acid tolerance is critical to bifidobacterial survival and their functionality. Thus, to explore the genes involved in the enhanced acid tolerance response and the crossprotection mechanism of JDM301AR, the transcriptional response profiles of JDM301 and JDM301AR were analyzed and compared under normal condition (cells were inoculated in modified MRS at an initial $\mathrm{pH}$ of 6.5 without stress and cultured under anaerobic condition at $37{ }^{\circ} \mathrm{C}$ ). A strong positive correlation $\left(\mathrm{R}^{2}=0.883\right)$ between RNA sequencing (RNA-Seq) data and real time quantitative polymerase chain reaction (RT-PCR) data was showed in Fig. 2. JDM301AR showed a total of 350 differentially expressed (DE) genes after adaptive evolution through successive batch

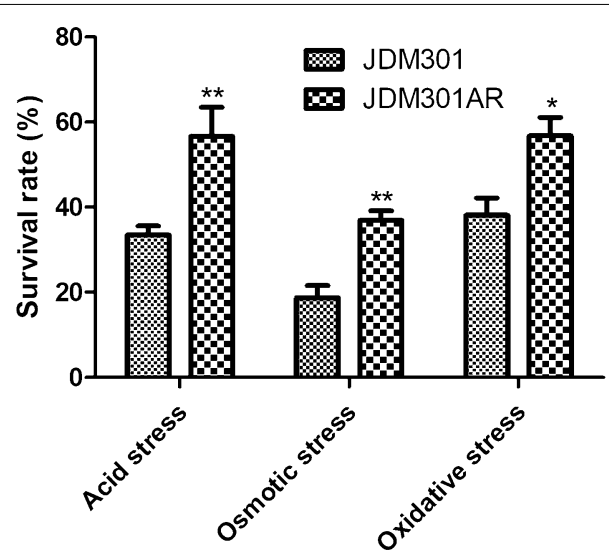

Fig. 1 Survival of Bifidobacterium longum JDM301 and JDM301AR under acid stress, osmotic stress or oxidative stress. Exponential cells were collected and resuspended into fresh modified MRS with low $\mathrm{pH}$ (3.5), or into modified MRS containing $1.25 \mathrm{mM} \mathrm{H}_{2} \mathrm{O}_{2}$ (oxidative stress) or $0.5 \mathrm{M} \mathrm{NaCl}$ (osmotic stress). Significant differences between JDM301 and JDM301AR under different conditions were marked. ${ }^{*} P<0.05 ;{ }^{*} P<0.01$ 


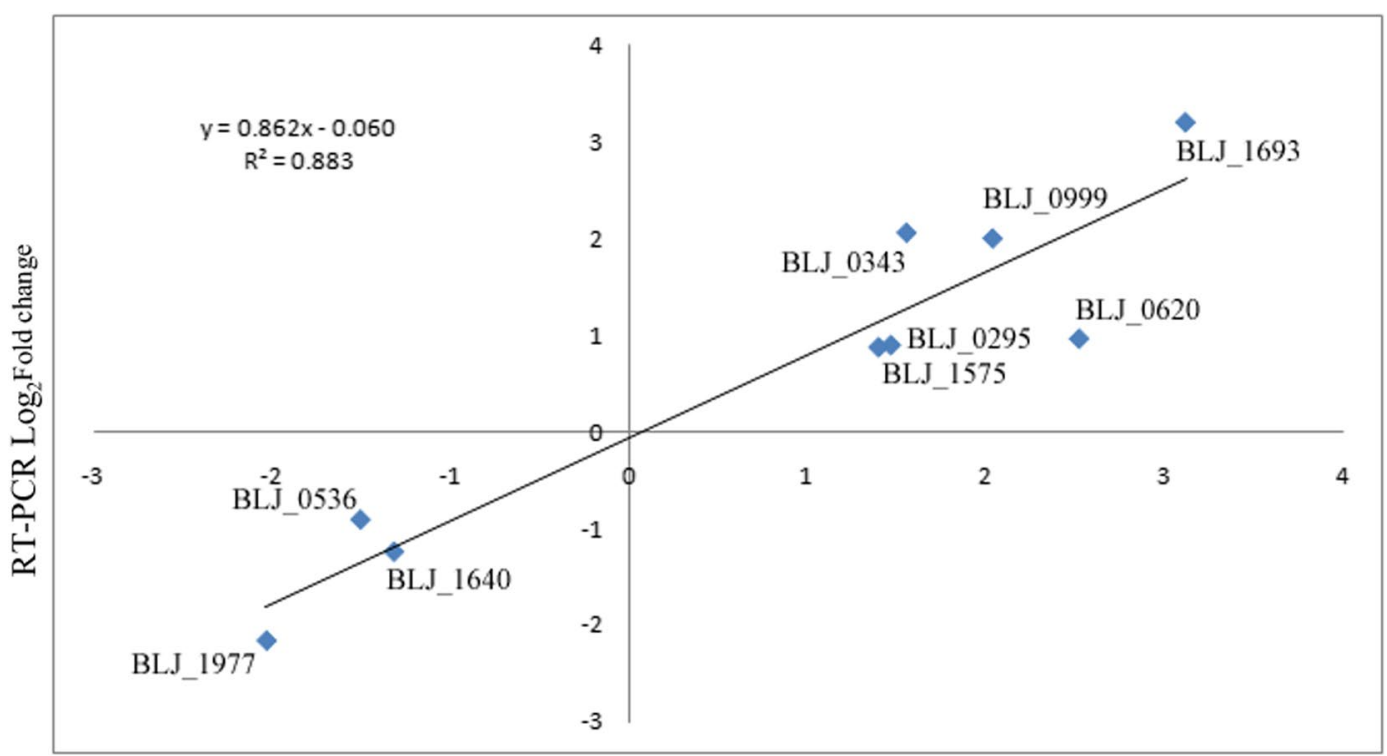

RNA-seq $\log _{2}$ Fold change

Fig. 2 Correlation of fold change values from RNA-Seq and real-time quantitative PCR results (RT-PCR). The best-fit curve was shown along with the calculated equation and $r^{2}$ value

cultures. Among the DE genes, 289 (82.6\%) were downregulated, while $61(17.4 \%)$ were upregulated (Fig. 3). Among them, BLJ_1400 $\left(\log _{2} \mathrm{FC}=1.6\right)$ encoding cystathionine gamma-synthase $\left(\mathrm{Met}_{3}\right)$ was upregulated in JDM301AR (Additional file 1). MetC $C_{3}$ can catalyze the combination of cysteine with succinylhomoserine to produce cystathionine [15]. Differently from the gene involved in production of cystathionine, genes encoding cystathionine lyase (BLJ_1778, $\log _{2} \mathrm{FC}=-10.1$ and BLJ_1779, $\left.\log _{2} \mathrm{FC}=-9.0\right)$ were all significantly downregulated (Additional file 1). The cystathionine can be converted to ammonia $\left(\mathrm{NH}_{3}\right)$, L-cysteine and $\alpha$-ketobutyrate by cystathionine gamma lyase (BLJ_1779) or $\mathrm{NH}_{3}$, L-homocysteine and pyruvate by cystathionine beta-lyase (BLJ_1778), when needed. Additionally, the cystathionine beta-lyase can catalyze the production of $\mathrm{NH}_{3}$ from L-cysteine [16]. $\mathrm{NH}_{3}$ can enhance the acid tolerance of bacteria by neutralizing $\mathrm{H}^{+}$. These results indicated that the ability to produce $\mathrm{NH}_{3}$ is promoted in JDM301AR by strengthening the $\mathrm{NH}_{3}$ reservation through accumulation of cystathionine. Borja et al. showed that the production of cystathionine gamma-synthase increased in an acid-resistant mutant obtained by incubated bifidobacteria at low $\mathrm{pH}$ medium [5], while the downregulation of cystathionine lyase has not been reported in acid tolerance response of bifidobacteria. Taken together, these results suggested that the ability to produce $\mathrm{NH}_{3}$ is promoted in JDM301AR by strengthening the $\mathrm{NH}_{3}$ reservation through accumulation of cystathionine, which was achieved through up-expression of $\mathrm{MetC}_{3}$ and downexpression of cystathionine lyase.

A gene cluster for pantothenate and CoA (Coenzyme A) biosynthesis (BLJ_0525-531) was upregulated in JDM301AR compared with JDM301 (Additional file 1). CoA is essential for central metabolism, including the degradation and synthesis of fatty acid (FA) and phospholipids synthesis [17]. CoA is derived from pantothenate and essential for the growth of organisms [18]. Reports showed that CoA biosynthesis played important roles in regulation of oxidative and osmotic stress response and that $\mathrm{CoA}$ also affected acid stress response by regulating protein acetylation [19-22]. These results suggested that the gene cluster may play important roles in the crossprotection of JDM301AR.

Furthermore, another gene cluster (BLJ_1300-1303) involved in peptidoglycan synthesis was also upregulated in JDM301AR (Additional file 1). Peptidoglycan is responsible for the rigidity of the bacterial cell wall, which is needed to cope with both high turgor pressure and environmental stress [23, 24]. It could be referred that strengthening the cell wall by enhancing peptidoglycan synthesis is one of the strategies of JDM301 and JDM301AR to response to adverse stress, including acid stress. These results implied that the enhanced synthesis of CoA and peptidoglycan play important roles in the cross-protection and the enhanced resistance of JDM301AR to acid stress. 


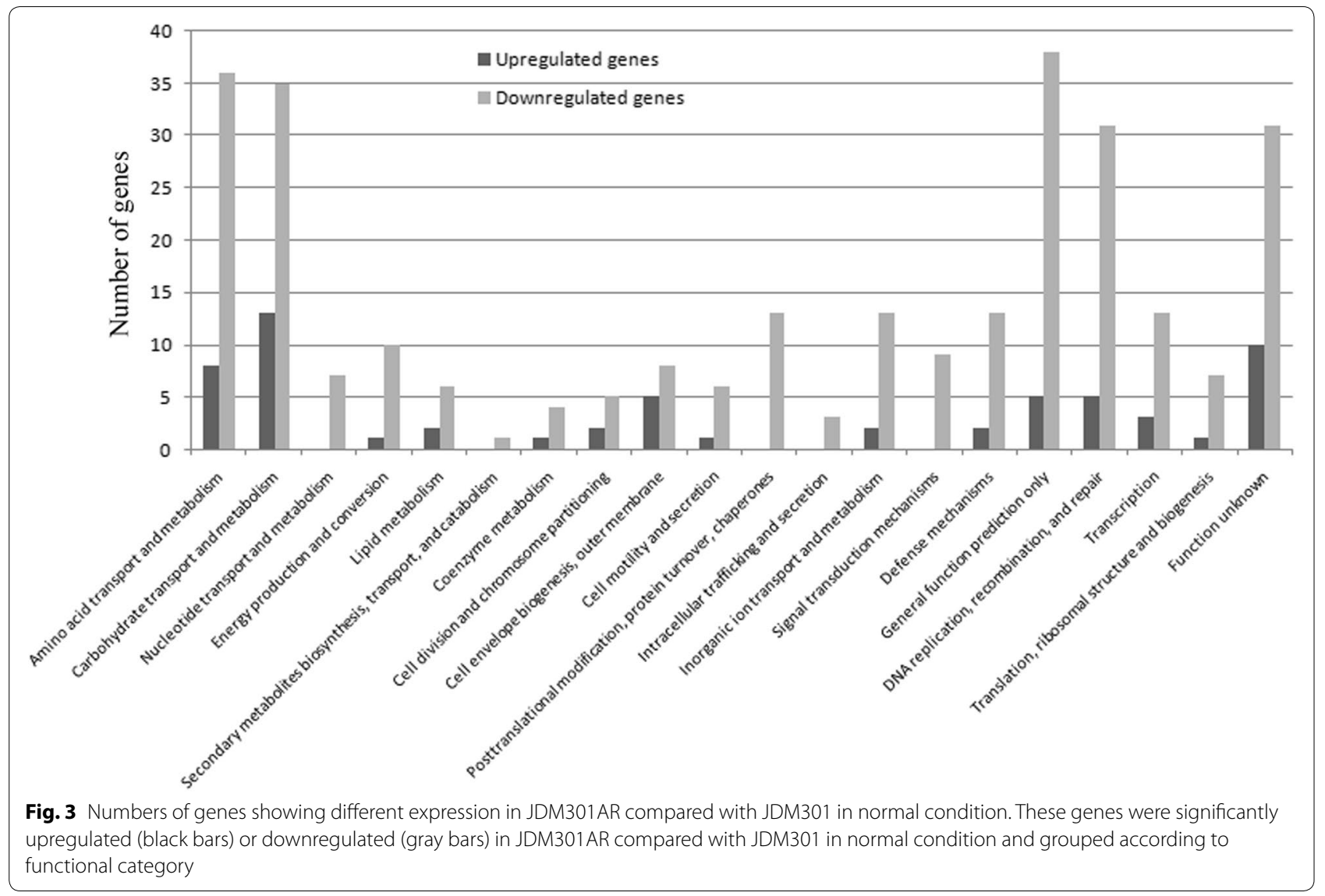

The expression of 7 genes involved in cell division and chromosome partitioning was changed (Additional file 1). Among them, FtsZ (BLJ_0917, $\log _{2} \mathrm{FC}=-2.4$ ) and other 4 proteins were downregulated. Only two proteins, SOS-response cell division inhibitor, SulA encoded by BLJ_1879 $\left(\log _{2} \mathrm{FC}=1.9\right)$ and an ATPase involved in chromosome partitioning encoded by BLJ_0570 $\left(\log _{2} \mathrm{FC}=1.1\right)$ were upregulated. SulA can inhibit FtsZ polymerization [25]. In previous reports, some bacteria survived various environmental stress, such as antibiotic treatment and oxidative stress by slowing growth down or growth arrest $[26,27]$. These results implied that the potentially decreased cell growth or division by down-regulating FtsZ may be helpful for Bifidobacterium to survive acid stress. Furthermore, SOS-response transcriptional repressors (LexA) encoded by BLJ_0655 $\left(\log _{2} \mathrm{FC}=1.1\right)$ was also upregulated. The two pieces of evidence indicated that the assembly of the $\mathrm{Z}$ ring may be prevented partially by upregulated SulA to protect daughter cells during cell division from the premature segregation of damaged DNA.

\section{Responses induced at low pH in JDM301 and JDM301AR}

When JDM301 was grown at pH 3.5, a total of 322 genes were upregulated compared with that at normal medium $(\mathrm{pH}=6.5)$ (Fig. 4a). When JDM301AR was cultured at $\mathrm{pH} 3.5$, a total of 263 genes were upregulated, which were smaller in number than JDM301 (Fig. 4b). These genes were grouped according to functional category and the percent of each functional category was shown in Fig. 4. The genes encoding ammonium transporter (BLJ_0220) in JDM301 $\left(\log _{2} \mathrm{FC}=1.7\right)$ and JDM301AR $\left(\log _{2} \mathrm{FC}=1.1\right)$ were both upregulated under acid stress, which suggested that the import of ammonium is enhanced to neutralize proton. Additionally, cystathionine gammasynthase (BLJ_1400) was also upregulated in JDM301 $\left(\log _{2} \mathrm{FC}=1.7\right)$ and JDM301AR $\left(\log _{2} \mathrm{FC}=2.0\right)$ (Additional file 2), which suggested that the ability to produce $\mathrm{NH}_{3}$ is promoted in both strains under acid stress.

\section{Different responses in peptidoglycan biosynthesis induced under $\mathrm{pH}$ challenge}

A total of 11 genes (BLJ_0153, BLJ_0225, BLJ_0390, BLJ_1055, BLJ_1847, BLJ_2036, BLJ_1295, BLJ_1297, 


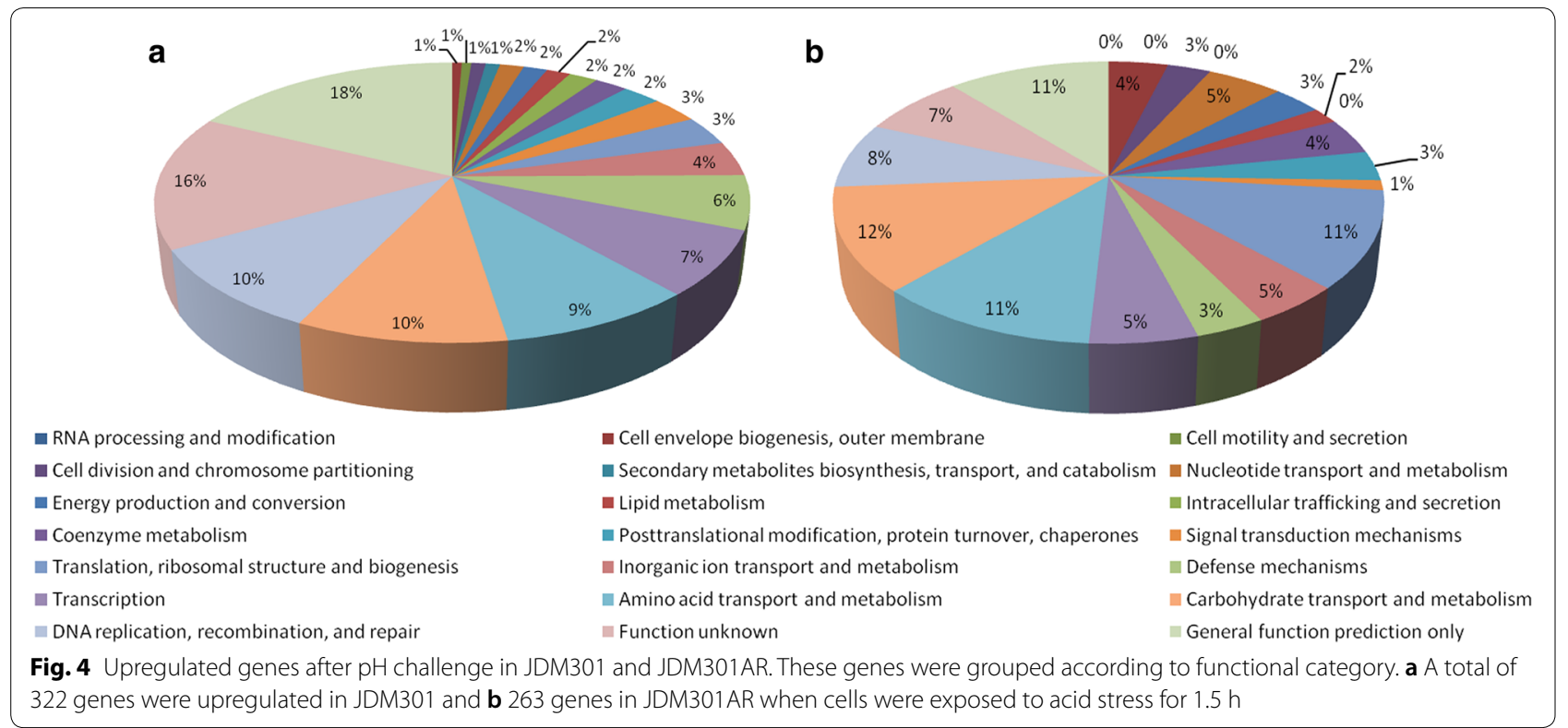

BLJ_1298, BLJ_1299, BLJ_1301) including a gene cluster (BLJ_1295-BLJ_1301) involved in peptidoglycan biosynthesis were upregulated at low pH in JDM301AR compared with normal condition (Additional file 2). However, only two of them (BLJ_0153, $\log _{2} \mathrm{FC}=1.2$ and BLJ_1299, $\log _{2} \mathrm{FC}=1.2$ ) were up-regulated by low $\mathrm{pH}$ in JDM301 (Additional file 2). The cell envelope and membrane (CEM) of bifidobacteria are mainly composed of peptidoglycan, lipid and exopolysaccharides. The CEM are probably the first targets of physicochemical stress [28]. These results suggested that the synthesis of peptidoglycan is further induced under acid stress in JDM301AR. Given that the genes of JDM301AR involved in peptidoglycan synthesis had been upregulated after successive batch cultures compared with JDM301 in normal condition, it can be inferred that the enhancement of peptidoglycan synthesis participates in acid stress adaptation of JDM301AR.

\section{Impact of low pH on the amino acid metabolism of JDM301 and JDM301AR}

The deamination of branched-chain amino acid (BCAA) has been postulated as a mechanism to maintain bacterial internal $\mathrm{pH}[6]$. Two genes (BLJ_1392, $\log _{2} \mathrm{FC}=1.5$; BLJ_1393, $\log _{2} F C=1.0$ ) in an operon involved in the transport of branched-chain amino acids (BCAA) were upregulated by low pH in JDM301AR (Additional file 2). An apparent operon (BLJ_0094- BLJ_0097) containing genes involved in BCAA transport, showed significant upregulation after acid stress in JDM301 (Additional file 2). These results suggest that the two operons might be used to promote deamination of BCAA and help cells cope with acid stress in the two strains, respectively.

Previous report showed that there were glutamate-, arginine- and lysine-dependent acid resistance pathways in bacteria [29]. In our study, a total of 53 genes participating in amino acid metabolism were upregulated, in which 4 genes for glutamate metabolism, 3 genes for arginine biosynthesis and 11 genes for the biosynthesis of essential amino acid lysine were discovered in JDM301AR exposed in acid stress. No downregulated genes in amino acid metabolism were detected in JDM301AR after acid challenge. The L-lysine biosynthesis via DAP pathway (BLJ_0147, BLJ_0149, BLJ_0489, BLJ_1832, BLJ_1564, BLJ_1831, BLJ_1383 and BLJ_1843) was activated in JDM301AR (Additional file 2). During the process, the homologs of diaminopimelate decarboxylase (BLJ_1843, $\log _{2} \mathrm{FC}=1.6$ ) were shown to specifically catalyze the decarboxylation of meso-diaminopimelate (meso-DAP) to L-lysine with a proton consumed from the cytoplasm [30]. For L-lysine biosynthesis via DAP pathway in parental strain, only 7 genes (BLJ_0147, BLJ_0149, BLJ_0489, BLJ_0490, BLJ_1299, BLJ_1383 and BLJ_1831) were upregulated after exposure to acid stress and the expression of BLJ_1843 was not changed (Additional file 2). The number of upregulated genes associated with amino acid metabolism in JDM301 was smaller (16 genes) than that of JDM301AR (Additional file 2). Furthermore, 8 genes involved in amino acid metabolism were downregulated in JDM301 (Additional file 2), when it was exposed to acid environment. Remarkably, among the downregulated genes, a gene cluster (including BLJ_0636-BLJ_0638, BLJ_0640 and BLJ_0642) 
encoding proteins responsible for arginine biosynthesis was found (Additional file 2). These results indicate that the organism's ability to consume cellular proton may be improved by enhancing lysine and arginine biosynthesis in JDM301AR.

\section{Influence of low-pH on membrane fatty acid (FA)}

The modification of FA in cell membrane plays an important role in acid tolerance response. Therefore, the membrane FA composition of JDM301 or JDM301AR was investigated after acid exposure. The FA profiles of JDM301 or JDM301AR were all dominated by two major FA (C16:0 and $\mathrm{C} 18: 0)$ both in normal condition and acid stress. Analysis showed no significant change in membrane composition in JDM301 cells grown in acidic medium for $1.5 \mathrm{~h}$ compared with cells grown in control medium (Fig. 5). The strain JDM301AR showed a significant increase $(\mathrm{p}<0.05)$ in $\mathrm{C} 14: 0$ after exposure to acid stress (Fig. 5a). Furthermore, direct comparison between the two strains showed dramatic difference in cells exposed to acid stress. JDM301AR in acidic medium for 1.5 $\mathrm{h}$ had more C14:0 than JDM301 exposed to acid stress (Fig. 5a). Previous reports showed that bacterial capability of changing its membrane FA composition could help it adapt to $\mathrm{pH}$ stress $[31,32]$. These results
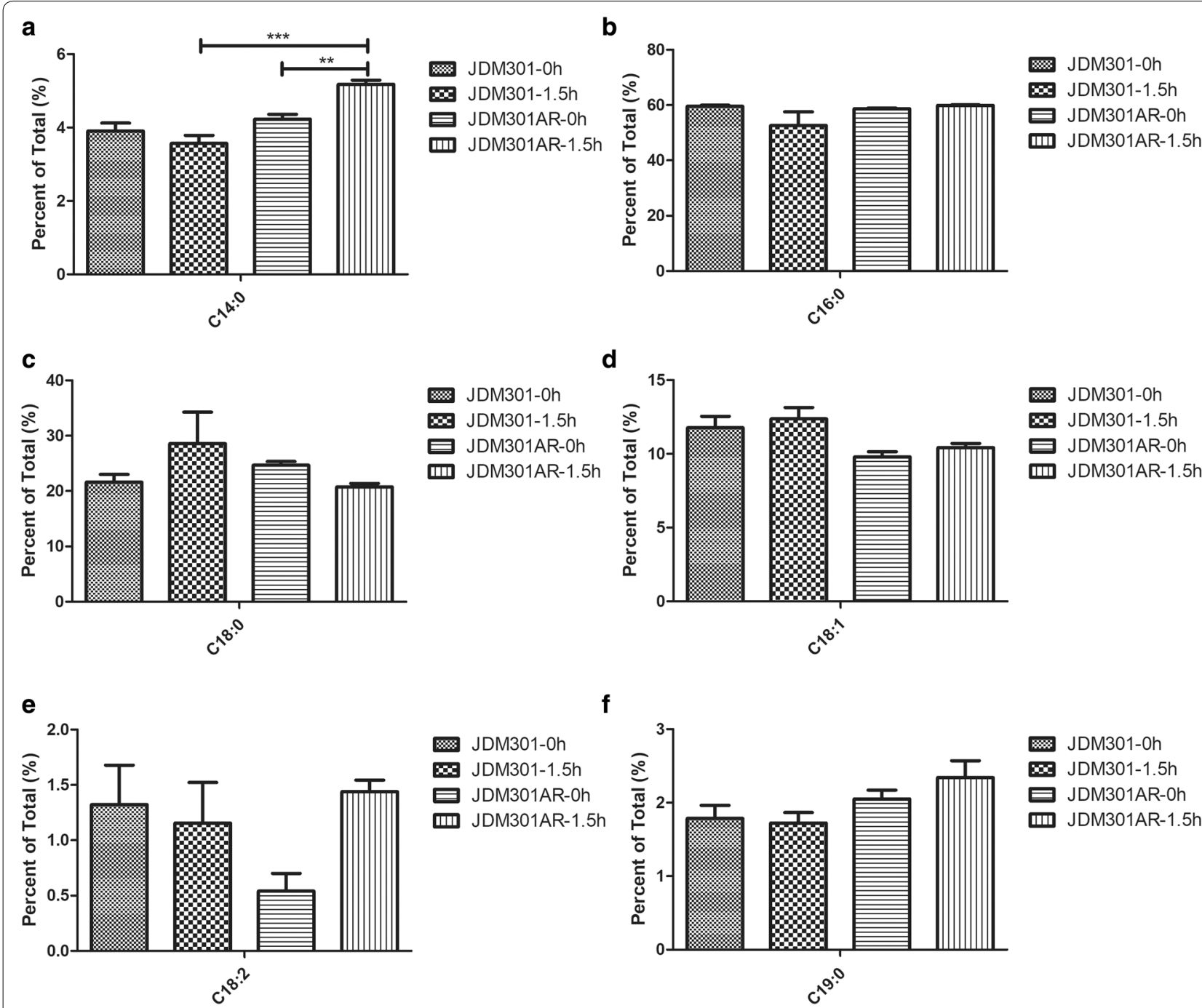

\section{f}

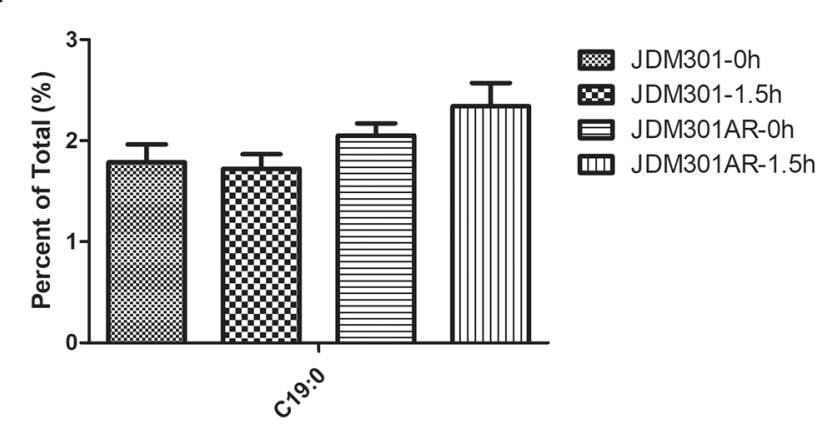

Fig. 5 Membrane fatty acid composition for JDM301 and JDM301AR. The graphs showed data from cells grown in MRS without acid stress and cells exposed to acidified MRS ( $\mathrm{pH}=3.5$ ) for $1.5 \mathrm{~h}$. The percentages of FAs in the membrane of JDM301 and JDM301AR under normal condition (0 h) or acid stress (1.5 $\mathrm{h}$ ) were shown. $\mathbf{a}$ The percentage of $\mathrm{C} 14: 0$; $\mathbf{b}$ the percentage of $\mathrm{C} 16: 0$; $\mathbf{c}$ the percentage of $\mathrm{C} 18: 0$; $\mathbf{d}$ the percentage of $\mathrm{C} 18: 1 ; \mathbf{e}$ the percentage of $\mathrm{C} 18: 2 ; \mathbf{f}$ the percentage of $\mathrm{C} 19: 0$. Error bars represent the standard error of the mean (SEM). ${ }^{* *} P<0.01,{ }^{* * *} P<0.001$ 
suggested that the increase of C14:0 may be helpful for JDM301AR to survive under acid stress.

In order to identify the basis for the differences in membrane lipid composition, the expression profiles of genes involved in FA metabolism were investigated in JDM301AR and JDM301 after exposure to acid stress. A total of 4 genes associated with FA metabolism were upregulated and no downregulated genes were found in response to acid stress in JDM301AR (Additional file 2). For JDM301, only 2 upregulated genes (BLJ_1756, $\log _{2} \mathrm{FC}=2.0$ and BLJ_1809, $\log _{2} \mathrm{FC}=1.5$ ) were detected and the two genes were also upregulated in JDM301AR (BLJ_1756, $\log _{2} \mathrm{FC}=1.4$ and BLJ_1809, $\log _{2} \mathrm{FC}=1.0$ ) under acid stress (Additional file 2). For JDM301AR, another two genes (BLJ_0565, $\log _{2} \mathrm{FC}=1.1$ and BLJ_1105, $\log _{2} \mathrm{FC}=1.2$ ) for FA metabolism were upregulated specifically in response to acid stress (Additional file 2). The reaction catalyzed by aldehyde dehydrogenase (ALDH) not only deactivates alkanals to convert them into FA, but also produces NADPH required for both the synthesis of FA and cell survival under stress conditions [33, 34]. The homolog of $A L D H$ gene (BLJ_0565) was specifically upregulated in JDM301AR under acid stress and may be used by JDM301AR to promote incorporation of FA into the cytomembrane by deactivating alkanals to FA. In addition, NADPH can reduce oxidized glutathione (GSSG) to glutathione (GSH) [35]. The expression of 4 genes (BLJ_0511, $\log _{2} \mathrm{FC}=1.9 ;$ BLJ_0624, $\log _{2} \mathrm{FC}=2.8 ;$ BLJ_0916, $\log _{2} \mathrm{FC}=1.2$ and BLJ_1324, $\log _{2} \mathrm{FC}=2.3$ ) involved in glutathione metabolism was upregulated in this strain, while only one gene (BLJ_0511, $\log _{2} \mathrm{FC}=1.7$ ) was up-regulated in JDM301. GSH could protect bacteria from acid stress, oxidative stress and osmotic stress by maintaining intracellular redox equilibrium [36, 37]. These results implied that BLJ_0565 may enhance cell survival ability under acid stress by promoting the production of FA and NADPH. The other specifically upregulated gene in JDM301AR, BLJ_1105 $\left(\log _{2} \mathrm{FC}=1.2\right)$ was predicted to encode a long-chain fatty acid coenzyme A (CoA) ligase. The gene was shown to activate exogenous long-chain fatty acids to incorporate into the cellular membrane, which might result in a different membrane lipid profile and promote JDM301AR survival under acid stress. Previous report showed that the mutation of long-chain fatty acid coenzyme A ( $\mathrm{CoA})$ ligase limited the ability of bifidobacterial strain to incorporate exogenous FA into its cytoplasmic membrane [38]. It was speculated that the up-regulated BLJ_0565 and BLJ_1105 may play important roles in the modification of membrane FA composition of JDM301AR after acid exposure.

\section{Conclusions}

The transcriptional and physiological data in this study revealed that successive batch cultures under standard condition can induce the acquisition of acid resistance. Furthermore, the adaptive response provided this bacterium with cross-protection against osmotic and oxdative stress. Compared with its parental strain, some differences in how the resistant strain overcome the acidic environment were presented, which could reflect the adaptation of the resistant strain to acid stress. Moreover, a shift in the FA composition of cell membrane was found, when the acid resistant strain, JDM301AR was exposed to low-pH environment. These results may be associated with the specifically upregulated homologs of aldehyde dehydrogenase and long-chain fatty acyl-CoA ligase. Overall, as a response to low $\mathrm{pH}$, the resistant strain may strengthening its resistance mainly by reinforcing amino acid metabolism, enhancing the generation and transport of $\mathrm{NH}_{3}$, modification of cell wall and cell member by remolding peptidoglycan biosynthesis and fatty acids metabolism. This study revealed the basis for understanding bifidobacterial acid tolerance response improved by successive batch cultures in normal condition without additional pressure.

\section{Methods}

\section{Bacterial strains and growth conditions}

Bifidobacterium longum JDM301, an industrial strain in China was used in this study. Bacteria were cultured in modified MRS broth (Difco, Leeuwarden, The Netherlands) supplemented with $0.05 \%(\mathrm{w} / \mathrm{v}) \mathrm{L}$-cysteine- $\mathrm{HCl}$ at $37^{\circ} \mathrm{C}$ under anaerobic conditions (Don Whitley Scientific Limited, West Yorkshire, The England) in an atmosphere of $5 \% \mathrm{CO}_{2}-5 \% \mathrm{H}_{2}-90 \% \mathrm{~N}_{2}$.

\section{Isolation of acid-resistant derivative of JDM301 (JDM301AR)}

Cells were inoculated in modified MRS at an initial $\mathrm{pH}$ of 6.5 and cultured under anaerobic condition for $24 \mathrm{~h}$. After growth under anaerobic condition for $24 \mathrm{~h}$, the cultures were adjusted to an optical density of 0.5 at $600 \mathrm{~nm}$ $\left(\mathrm{OD}_{600}\right)$ and sub-cultured $(10 \%, 0.3 \mathrm{ml}$ in a total volume of $3 \mathrm{ml})$ in fresh modified MRS ( $\mathrm{pH}=6.5)$. These cultures were incubated at $37^{\circ} \mathrm{C}$ for $24 \mathrm{~h}$ at the same condition for 150 repeats. Then the steps were repeated and colonies were isolated from the 150th repeats (Adapted strain, JDM301AR).

\section{Stress tolerance test}

After 150 repeats, stress tolerance test was performed to reveal the potential difference of survival ability upon acid stress, oxidative or osmotic stress between 
JDM301AR and its parental strain JDM301. The cultures of B. longum JDM301 (Non-adapted strain, JDM301) and the isolated colonies of the 150th repeats (JDM301AR) were prepared by two successive transfers into modified MRS [10\% inoculum (v/v)]. Cells cultured for about $16 \mathrm{~h}$ were used to perform stress tolerance tests. The survival ability was determined under acid stress $(\mathrm{pH} 3.5)$, oxidative stress $\left(1.25 \mathrm{mM} \mathrm{H}_{2} \mathrm{O}_{2}\right)$ or osmotic stress $(0.5 \mathrm{M}$ $\mathrm{NaCl}$ ). The cultures were transferred into acidified liquid MRS medium $(\mathrm{pH}=3.5)$ and inoculated under anaerobic condition at $37{ }^{\circ} \mathrm{C}$ for $1.5 \mathrm{~h}$ to test the survival ability under acid stress. Similarly, cultures were transferred into the MRS supplemented with $0.5 \mathrm{M} \mathrm{NaCl}$ or the MRS with the addition of $1.25 \mathrm{mM} \mathrm{H}_{2} \mathrm{O}_{2}$ to test the survival ability under oxidative stress and osmotic stress, respectively. After anaerobic incubation at $37^{\circ} \mathrm{C}$ for $1.5 \mathrm{~h}$, the surviving cells were counted by plate count on MRS agar medium.

\section{RNA isolation}

Cultures from $3 \mathrm{ml}$ samples incubated under the condition above were harvested by centrifugation. Cell pellets $\left(\sim 1 \times 10^{9}\right.$ cells $)$ were suspended in $1 \mathrm{ml}$ Trizol Reagent and disrupted with benchtop homogenizer (MP Biomedicals, California, USA). Then total RNA was extracted and the quantity of RNA was determined by a NanoDrop spectrophotometer (ThermoFisher Scientific, Waltham, MA). The quality of RNA was assayed using an Agilent 2100 bioanalyzer (Agilent Technologies, Waldbronn, Germany).

\section{RNA sequencing}

The total RNA with RNA integrity number $>8.0$ was treated with DNaseI (Takara, Janpan). Then mRNA was purified using a Dynabeads mRNA purification Kit (Life Technologies, USA). The cDNA library was constructed using NEBNext UltraTM RNA Library Pre Kit for Illumina (NEB, USA) according to manufacturer' protocol. A cDNA library was sequenced using an Illumina HiseqTM2500 sequencer according to the manufacturer' instructions. For each sample, about five million pair-end reads $(2 \times 150 \mathrm{bp})$ were obtained for further analysis. All sequenced reads were aligned to the genome of $B$. longum JDM301 and the sequences were deposited in NCBI Sequence Read Archive (SRA) database under accession number PRJNA555155. All these uniquely mapped reads were used to calculate the RPKM values (Reads per kilobase of exon per million mapped sequenced reads) of genes. It indicated the normalized gene expression level. MARS (MA-plot-based method with Random sampling model) in an R package DEGseq was used to identify differentially expressed genes (DEGs) from different samples, $|\mathrm{FC}|>2$; fdr $<0001$ [39].

\section{RT-PCR assays}

Validation of RNA sequencing data was performed by RT-PCR. The primers of selected genes were designed using Primer 5 based on the complete genome sequences of JDM301. The primers used were shown in additional file 3. Total RNA (2ug) was used to yield cDNA as template for RT-PCR using the Revert Aid First Strand cDNA Synthesis Kit (Fermentas, Waltham, USA). RT-PCR was performed using the Fast Start Universal SYBR Green Master (Rox, Roche) and using the following conditions: $95^{\circ} \mathrm{C}$ for $10 \mathrm{~min}$, followed by 40 cycles at $95^{\circ} \mathrm{C}$ for $15 \mathrm{~s}$, $58{ }^{\circ} \mathrm{C}$ for $30 \mathrm{~s}$ and $72{ }^{\circ} \mathrm{C}$ for $30 \mathrm{~s}$. The $16 \mathrm{~S}$ rDNA gene was used as an internal standard. Calculations were performed using the $2^{-\Delta \Delta C T}$ method to determine the relative gene expression [40].

\section{Analysis of the fatty acid composition}

The membrane fatty acid composition of the cells was determined by a previously reported method with a few modifications. Briefly, cells were grown in batch cultures under the condition above. Cells in $20 \mathrm{ml}$ samples were collected by centrifugation and washed by phosphatebuffered saline. Then membrane fatty acids were isolated from the pelleted cells and identified using gas chromatography as previously reported $[41,42]$.

\section{Supplementary information}

Supplementary information accompanies this paper at https://doi. org/10.1186/s12934-019-1206-X.

Additional file 1. List of genes involved in $\mathrm{NH}_{3}$ production, peptidoglycan synthesis, pantothenate and CoA biosynthesis and cell division and chromosome partitioning expressed differently in JDM301AR compared with JDM301 in normal condition.

Additional file 2. Differently expressed genes involved in peptidoglycan biosynthesis, metabolism and transport of amino acid and fatty acid metabolism in JDM301AR and JDM301 or in the two strains after exposure to acid stress.

Additional file 3. Primers used in RT-PCR for validation of RNA sequencing data.

\section{Acknowledgements}

Not applicable.

\section{Authors' contributions}

$D L$ and $Y W$ designed the study; YW, JG and WL analyzed the data; JG, WL and YL carried out the experiments; YW wrote the paper and DL edited the paper. All authors read and approved the final manuscript.

Funding

This work was funded by the National Natural Science Foundation of China (Grant No. 31300029 and Grant No. 81970730), the Natural Science Foundation of Jiangsu Province, China (BK20130213), the Scientific Research Foundation of Xuzhou Medical University (2015KJ06), the Program for Youth Science and Technology Innovative Research Team of Xuzhou Medical University, the Scientific Research Foundation for the Talents of Xuzhou Medical University (D2012014), Top-notch Academic Programs Project of Jiangsu Higher Education Institutions (TAPP) (PPZY2015B161), a Project Funded by the Priority 
Academic Program Development of Jiangsu Higher Education Institutions (PAPD), National Demonstration Center for Experimental Basic Medical Science Education (Xuzhou Medical University) and was sponsored by Jiangsu Overseas Visiting Scholar Program for University Prominent Young \& Middleaged Teachers and Presidents, the Qing Lan Project of Jiangsu Province, the 333 Project of Jiangsu Province, China. The funders had no role in the study design, data collection or interpretation, or the decision to submit the work for publication.

\section{Ethics approval and consent to participate}

Not applicable.

\section{Competing interests}

The authors declare that they have no competing interests.

Received: 6 June 2019 Accepted: 4 September 2019

Published online: 12 September 2019

\section{References}

1. Hidalgo-Cantabrana C, Delgado S, Ruiz L, Ruas-Madiedo P, Sanchez B, Margolles A. Bifidobacteria and their health-promoting effects. Microbiol Spectr. 2017. https://doi.org/10.1128/microbiolspec.BAD-0010-2016.

2. Wei YX, Ye L, Liu DB, Zhang ZY, Liu C, Guo XK. Activation of the chromosomally encoded mazEF(Bif) locus of Bifidobacterium longum under acid stress. Int J Food Microbiol. 2015;207:16-22.

3. Meance S, Cayuela C, Turchet P, Raimondi A, Lucas C, Antoine JM. Afermented milk with a Bifidobacterium probiotic strain DN-173 010 shortened oro-fecal gut transit time in elderly. Microb Ecol Health Dis. 2001:13:217-22.

4. Matias NS, Padilha M, Bedani R, Saad SMI. In vitro gastrointestinal resistance of Lactobacillus acidophilus La-5 and Bifidobacterium animalis Bb-12 in soy and/or milk-based synbiotic apple ice creams. Int J Food Microbiol. 2016;234:83-93.

5. Sanchez B, Champomier-Verges MC, Collado Mdel C, Anglade P, Baraige F, Sanz Y, Reyes-Gavilan CG, Margolles A, Zagorec M. Low-pH adaptation and the acid tolerance response of Bifidobacterium longum biotype longum. Appl Environ Microbiol. 2007;73:6450-9.

6. Len AC, Harty DW, Jacques NA. Proteome analysis of Streptococcus mutans metabolic phenotype during acid tolerance. Microbiology. 2004:150:1353-66.

7. Flahaut S, Hartke A, Giard JC, Benachour A, Boutibonnes P, Auffray Y. Relationship between stress response toward bile salts, acid and heat treatment in Enterococcus faecalis. FEMS Microbiol Lett. 1996;138:49-54.

8. Wei Y, Yang F, Wu Q, Gao J, Liu W, Liu C, Guo X, Suwal S, Kou Y, Zhang $B$, et al. Protective effects of bifidobacterial strains against toxigenic Clostridium difficile. Front Microbiol. 2018;9:888.

9. Wei Y, Li Y, Yang F, Wu Q, Liu D, Li X, Hua H, Liu X, Wang Y, Zheng K, Tang R: Physical and Functional Interplay between MazF1(Bif) and Its Noncognate Antitoxins from Bifidobacterium longum. Appl Environ Microbiol 2017, 83.

10. Yurtsev EA, Conwill A, Gore J. Oscillatory dynamics in a bacterial crossprotection mutualism. Proc Natl Acad Sci USA. 2016;113:6236-41.

11. Vattanaviboon P, Mongkolsuk S. Unusual adaptive, cross protection responses and growth phase resistance against peroxide killing in a bacterial shrimp pathogen, Vibrio harveyi. FEMS Microbiol Lett. 2001;200:111-6.

12. Hartke A, Bouche $S$, Gansel X, Boutibonnes P, Auffray Y. Starvationinduced stress resistance in Lactococcus lactis subsp. lactis IL1403. Appl Environ Microbiol. 1994;60:3474-8.

13. Sanchez B, Ruiz L, Gueimonde M, Ruas-Madiedo P, Margolles A. Adaptation of bifidobacteria to the gastrointestinal tract and functional consequences. Pharmacol Res. 2013;69:127-36.

14. Svanback R, Pineda-Krch M, Doebeli M. Fluctuating population dynamics promotes the evolution of phenotypic plasticity. Am Nat. 2009;174:176-89.

15. Jaworski AF, Lodha PH, Manders AL, Aitken SM. Exploration of the active site of Escherichia coli cystathionine gamma-synthase. Protein Sci. 2012;21:1662-71.
16. Irmler S, Schafer $H$, Beisert B, Rauhut $D$, Berthoud $H$. Identification and characterization of a strain-dependent cystathionine beta/gamma-lyase in Lactobacillus casei potentially involved in cysteine biosynthesis. FEMS Microbiol Lett. 2009;295:67-76.

17. Ernst DC, Downs DM. The STM4195 gene product (PanS) transports coenzyme A precursors in Salmonella enterica. J Bacteriol. 2015;197:1368-77.

18. Thomas J, Cronan JE. Antibacterial activity of N-pentylpantothenamide is due to inhibition of coenzyme a synthesis. Antimicrob Agents Chemother. 2010;54:1374-7.

19. Tsuchiya Y, Zhyvoloup A, Bakovic J, Thomas N, Yu BYK, Das S, Orengo C, Newell C, Ward J, Saladino G, et al. Protein CoAlation and antioxidant function of coenzyme A in prokaryotic cells. Biochem J. 2018;475:1909-37.

20. Rubio S, Whitehead L, Larson TR, Graham IA, Rodriguez PL. The coenzyme a biosynthetic enzyme phosphopantetheine adenylyltransferase plays a crucial role in plant growth, salt/osmotic stress resistance, and seed lipid storage. Plant Physiol. 2008;148:546-56.

21. Siudeja K, Srinivasan B, Xu L, Rana A, de Jong J, Nollen EA, Jackowski S, Sanford L, Hayflick S, Sibon OC. Impaired Coenzyme A metabolism affects histone and tubulin acetylation in Drosophila and human cell models of pantothenate kinase associated neurodegeneration. EMBO Mol Med. 2011;3:755-66.

22. Castano-Cerezo S, Bernal V, Post H, Fuhrer T, Cappadona S, Sanchez-Diaz NC, Sauer U, Heck AJ, Altelaar AF, Canovas M. Protein acetylation affects acetate metabolism, motility and acid stress response in Escherichia coli. Mol Syst Biol. 2014;10:762.

23. Horcajo P, de Pedro MA, Cava F. Peptidoglycan plasticity in bacteria: stress-induced peptidoglycan editing by noncanonical D-amino acids. Microb Drug Resist. 2012;18:306-13.

24. Botella H, Vaubourgeix J, Lee MH, Song N, Xu W, Makinoshima H, Glickman MS, Ehrt S. Mycobacterium tuberculosis protease MarP activates a peptidoglycan hydrolase during acid stress. EMBO J. 2017;36:536-48.

25. Mukherjee A, Cao C, Lutkenhaus J. Inhibition of FtsZ polymerization by SulA, an inhibitor of septation in Escherichia coli. Proc Natl Acad Sci U S A. 1998;95:2885-90.

26. Cheverton AM, Gollan B, Przydacz M, Wong CT, Mylona A, Hare SA, Helaine $S$. A salmonella toxin promotes persister formation through acetylation of tRNA. Mol Cell. 2016;\$1097-2765:30139.

27. Tiwari P, Arora G, Singh M, Kidwai S, Narayan OP, Singh R. MazF ribonucleases promote Mycobacterium tuberculosis drug tolerance and virulence in guinea pigs. Nat Commun. 2015;6:6059.

28. Chang YY, Cronan JE Jr. Membrane cyclopropane fatty acid content is a major factor in acid resistance of Escherichia coli. Mol Microbiol. 1999;33:249-59.

29. Diez-Gonzalez F, Karaibrahimoglu Y. Comparison of the glutamate-, arginine- and lysine-dependent acid resistance systems in Escherichia coli O157:H7. J Appl Microbiol. 2004;96:1237-44.

30. Kandiah E, Carriel D, Perard J, Malet H, Bacia M, Liu K, Chan SW, Houry WA, Choudens S, Elsen S, Gutsch I. Structural insights into the Escherichia coli lysine decarboxylases and molecular determinants of interaction with the AAA + ATPase RavA. Sci Rep. 2016;6:24601.

31. van Schaik W, Gahan CG, Hill C. Acid-adapted Listeria monocytogenes displays enhanced tolerance against the lantibiotics nisin and lacticin 3147. J Food Prot. 1999;62:536-9.

32. Liu S, Ren F, Jiang J, Zhao L. Acid Response of Bifidobacterium longum subsp. longum BBMN68 is accompanied by modification of the cell membrane fatty acid composition. J Microbiol Biotechnol. 2016;26:1190-7.

33. Trautmann D, Beyer P, Al-Babili S. The ORF slr0091 of Synechocystis sp. PCC6803 encodes a high-light induced aldehyde dehydrogenase converting apocarotenals and alkanals. FEBS J. 2013;280:3685-96.

34. Jo JE, Mohan Raj S, Rathnasingh C, Selvakumar E, Jung WC, Park S. Cloning, expression, and characterization of an aldehyde dehydrogenase from Escherichia coli K-12 that utilizes 3-Hydroxypropionaldehyde as a substrate. Appl Microbiol Biotechnol. 2008;81:51-60.

35. Yin $\mathrm{H}$, Zhang R, Xia M, Bai X, Mou J, Zheng Y, Wang M. Effect of aspartic acid and glutamate on metabolism and acid stress resistance of Acetobacter pasteurianus. Microb Cell Fact. 2017;16:109.

36. Smimova GVOO. Glutathione in bacteria. Biochemistry. 2005;70:1199-211.

37. Zhang J, Fu RY, Hugenholtz J, Li Y, Chen J. Glutathione protects Lactococcus lactis against acid stress. Appl Environ Microbiol. 2007;73:5268-75. 
38. Oberg TS, Ward RE, Steele JL, Broadbent JR. Genetic and physiological responses of Bifidobacterium animalis subsp. lactis to hydrogen peroxide stress. J Bacteriol. 2013;195:3743-51.

39. Wang L, Feng Z, Wang X, Zhang X. DEGseq: an R package for identifying differentially expressed genes from RNA-seq data. Bioinformatics. 2010;26:136-8.

40. Livak KJ, Schmittgen TD. Analysis of relative gene expression data using real-time quantitative PCR and the 2(-Delta Delta C(T)) Method. Methods. 2001;25:402-8.

41. Sasser M. Identification of bacteria by gas chromatography of cellular fatty acids. technical note 101. Newark: Midi Inc; 1990.
42. Oberg TS, Ward RE, Steele $J$, Broadbent JR. Identification of plasmalogens in the cytoplasmic membrane of Bifidobacterium animalis subsp lactis. Appl Environ Microbiol. 2012;78:880-4.

\section{Publisher's Note}

Springer Nature remains neutral with regard to jurisdictional claims in published maps and institutional affiliations.
Ready to submit your research? Choose BMC and benefit from:

- fast, convenient online submission

- thorough peer review by experienced researchers in your field

- rapid publication on acceptance

- support for research data, including large and complex data types

- gold Open Access which fosters wider collaboration and increased citations

- maximum visibility for your research: over $100 \mathrm{M}$ website views per year

At BMC, research is always in progress.

Learn more biomedcentral.com/submissions 